\title{
Anxiety in Pregnancy and its Correlates: A Cross Sectional Study
}

\section{Sharma $\mathbf{R}^{1}$, Bhattarai $\mathbf{G}^{2 *}$ and Thapa $\mathbf{P}^{3}$}

${ }^{1}$ Consultant Psychiatrist, Medicare National Hospital and Research Centre, Nepal

${ }^{2}$ Lecturer, Department of Psychiatry, Patan Academy of Health Sciences, Nepal

${ }^{3}$ Assistant Professor, Department of Psychiatry, Manipal College of Medical

Sciences, Nepal

*Corresponding Author: Bhattarai G, Lecturer, Department of Psychiatry, Patan

Academy of Health Sciences, Nepal.
Received: May 27, 2021

Published: June 23, 2021

(C) All rights are reserved by Bhattarai G., et al.

\begin{abstract}
Introduction: Pregnancy increases the risk of various psychiatric symptoms including anxiety. Such symptoms can have negative consequences in pregnancy and post-partum. Adverse fetal outcome such as prematurity, low birth weight and post-partum psychiatric issues in mother have been seen in women who suffer from psychiatric illness during pregnancy. Psychiatric disorders among pregnant women are still undiagnosed and untreated. In spite of the adverse consequences that pregnancy-related mental illnesses can induce, very few studies have identified psychiatric illnesses among this group of women in developing countries like Nepal. The aim of this study was to find out the prevalence and correlates of anxiety among pregnant women.

Method: A cross-sectional, hospital based, descriptive study was conducted among 135 pregnant women attending Manipal Teaching Hospital, Pokhara (Nepal) antenatal clinic. Sociodemographic data and relevant clinical variables were collected using a predesigned pro forma after obtaining informed written consent. The subjects were interviewed with Hit Insult Threaten, Scream (HITS) scale and Beck's Anxiety Inventory (BAI). For the assessment of correlates, regression analysis was carried out. All statistical analyses were done using SPSS v 20.0. P values $<0.05$ were considered significant.

Result: The prevalence of anxiety in this sample was found to be $9.6 \%$. Factors such as history of sub fertility, pregnancy-induced illnesses and presence of domestic violence were found to be statistically significant predictors of anxiety during pregnancy.

Conclusion: Certain factors correlate with development of anxiety during pregnancy. Pregnant women with risk factors should be screened and diagnosed for timely treatment.
\end{abstract}

Keywords: Pregnancy; Mental Illness; Anxiety; Risk Factors

\section{Abbreviations}

WHO: World Health Organization; OPD: Out Patient Department; HITS: Hit, Insult, Threaten, Scream Scale; BAI: Beck Anxiety Inventory; ANC: Ante-Natal Clinic; POG: Period of Gestation

\section{Introduction}

Pregnancy can be a time of joy and fulfillment for many women. However, pregnancy also demands adjustment to profound chang- es in form and physiology of the body. Such physiological changes along with changes in life style, change in perception of self-image and the burden of personal and societal expectations regarding parenting can bring about mental illness in the pregnant woman. Various psychiatric issues including anxiety have been identified in pregnancy.

Anxiety disorders are higher in pregnant as compared to non-pregnant women. Its prevalence is second to depression in 
the pregnant population [1]. One study, with 207 pregnant participants, revealed that $15 \%$ of participants showed high score of anxiety in $1^{\text {st }}$ trimester and $12.3 \%$ in second trimester. The highest prevalence was seen in $3^{\text {rd }}$ trimester, with $18.2 \%$ of participants having anxiety symptoms [2]. In a study of 712 women in southern Brazil, measuring psychiatric comorbidity during pregnancy, the $2^{\text {nd }}$ most prevalent diagnosis was identified as generalized anxiety disorder (19.8\%) [3].

World Health Organization (WHO) has identified the following risk factors in low and middle-income countries as being implicated in anxiety and depression in pregnancy: adolescent pregnancy, being unmarried or separated, unwanted pregnancy, maladjusted marital relationship, history of stillbirth/repeated miscarriage, nulliparity, lack of financial resources, pregnancy as a result of rape, domestic violence and difficult relationship with in-laws. Although anxiety is a common issue seen during pregnancy, it is either unidentified or insufficiently treated. Also, anxiety during pregnancy warrants special attention as it can lead to deleterious effects in overall health of the mother and the child. Anxiety is a risk factor for adverse events during as well as after pregnancy as well . Preterm labor, frequent hospital admissions and increased need of pain relief during labor are seen in pregnant women with anxiety disorders [1].

\section{Aim of the Study}

This study aims to highlight the various features of this important health concern with a view that proper screening and diagnosis of anxiety will bring early intervention to the needy thus preventing various complications and ensuring a healthy motherinfant bonding and development.

\section{Methodology}

A hospital based, cross sectional, observational study was conducted in the out-patient department(OPD) of Department of Psychiatry, Manipal Teaching Hospital after obtaining approval from Institutional Review Committee of the same institution.

Inclusion criteria were: 1 . Pregnant females in all trimesters attending antenatal care clinic 2. Those who give consent. Exclusion Criteria were: 1 . Patients who fail to give consent 2 . Patients suffering from a serious medical illness.

A minimum sample size of 90 was calculated using the formula of sample size for regression, where the number of predictors was assumed to be 5 . A total sample size of 135 was taken. Data was collected by the first author after getting informed written consent from participants. A pre-structured proforma was used to gather information regarding socio-demographic variables, pregnancy related variables together with Hit, Insult, Threaten, Scream (HITS) scale which was used to assess for domestic violence which was followed by scale that measured anxiety i.e., Beck's Anxiety Inventory (BAI).

Tools

- Hit Insult Threaten Scream Scale (HITS): It is a short screening tool consisting of four items namely show often their partner physically hurt, Insulted, threatened with harm, or screamed at them. Frequency of such activity is measured in five-point scale with 1 denoting never to 5 denoting frequently. If score of more than 10 is obtained, it is said to be positive. Cronbach's alpha value of the scale is found to be 0.80 [4].

- Beck Anxiety Inventory (BAI): It is a scale developed by Aaron T. Beck and colleagues [5]. It consists of 21 questions. It has been commonly used to assess anxiety in populations. It is a self-report tool for anxiety. Each question is scored from 0 to 3. For interpretation of total scores, 0 - 21 is considered low or normal anxiety, 22 - 35 is moderate anxiety and score more than 36 is considered to be severe anxiety. Nepali version is available and has been validated. Its sensitivity is found to be 0.77 and specificity $=0.81$ with Cronbach's $\alpha=0.90[6]$.

\section{Results}

Characteristics of study population

The current study included 135 patients. The age of participants ranged from 17 years to 39 years with mean age of 24.90 years ( $\mathrm{SD}=4.54)$. Among them, $74.8 \%$ were residing in an urban area with majority (43.7\%) having secondary level education and $56.3 \%$ falling into lower middle economic class. $1.5 \%$ of the study population were widowed during the present pregnancy period whereas $98.5 \%$ were married. $58.5 \%$ of the study population were residing in extended family during time of the study. $8.1 \%$ of the study population had preexisting medical illness and $3 \%$ had a family history of mental illness. Regarding presence of domestic violence, $4.4 \%$ of study population fulfilled criteria for domestic violence according to HITS scale. 
Pregnancy related variables are presented in table 1.

\begin{tabular}{|c|c|c|c|}
\hline Variable & & Frequency & Percentage \\
\hline \multirow{2}{*}{$\begin{array}{l}\text { Past history of mental } \\
\text { illness in pregnancy }\end{array}$} & Yes & 6 & 4.4 \\
\hline & No & 129 & 95.6 \\
\hline \multirow{6}{*}{$\begin{array}{l}\text { Number of past } \\
\text { pregnancies }\end{array}$} & 0 & 61 & 45.2 \\
\hline & 1 & 43 & 31.9 \\
\hline & 2 & 25 & 18.5 \\
\hline & 3 & 4 & 3 \\
\hline & 4 & 0 & 0 \\
\hline & 5 & 2 & 1.5 \\
\hline \multirow{2}{*}{$\begin{array}{l}\text { Complication in } \\
\text { previous pregnancies }\end{array}$} & Yes & 49 & 36.3 \\
\hline & No & 86 & 63.7 \\
\hline \multirow{2}{*}{ History of subfertility } & Yes & 8 & 5.9 \\
\hline & No & 127 & 94.1 \\
\hline \multirow{2}{*}{ Planned pregnancy } & Yes & 109 & 80.7 \\
\hline & No & 26 & 19.3 \\
\hline \multirow{2}{*}{$\begin{array}{l}\text { Pregnancy induced } \\
\text { illness }\end{array}$} & yes & 20 & 14.8 \\
\hline & No & 115 & 85.2 \\
\hline \multirow{3}{*}{ Expected outcome } & Son & 41 & 30.4 \\
\hline & Daughter & 22 & 16.3 \\
\hline & Any & 72 & 53.3 \\
\hline
\end{tabular}

Table 1: Pregnancy related variables.

\section{Prevalence of anxiety}

Table below shows the prevalence of anxiety among study population according to BAI. Patients with low level of anxiety had the highest frequency with $90.4 \%$ followed by moderate anxiety in $9.6 \%$. In this study group, none of the study population fulfilled the criteria for severe anxiety.

\begin{tabular}{|l|c|c|}
\hline & Frequency & Percentage \\
\hline Low & 122 & 90.4 \\
\hline Moderate & 13 & 9.6 \\
\hline Severe & 0 & 0 \\
\hline Total & 135 & 100 \\
\hline
\end{tabular}

Table 2: Severity of anxiety according to BAI.

\section{Association of Anxiety and different variables}

The table below shows the relationship of BAI with different sociodemographic and pregnancy related variables. The table shows that among participants with anxiety and participants without anxiety there was with statistically significant difference in patients with history of infertility $(\mathrm{p}<0.001)$ and in pregnancies with complications in the present pregnancy $(\mathrm{p}<0.001)$.

\section{Correlates of anxiety in pregnancy}

Multiple regression was performed keeping total BAI score as the dependent variable and age, marital status, history of infertility, complication of previous pregnancy, planned pregnancy, expected pregnancy, HITS and pregnancy induced illness as independent variables. Our analysis showed that all these variables explained $39 \%$ of variance in BAI. Out of all the independent variables only history of infertility, HITS and pregnancy induced illness statistically significantly predicted BAI score as shown in table below.

\section{Discussion}

This study included 135 pregnant females attending the antenatal clinic of Manipal College of Medical Sciences.

Within the subjects, 23\% were between age group 15 - 20 years, $62 \%$ were between age group 21 - 25, 35\% were between 26 - 30, $12 \%$ were between 31 - 35 and reaming 3\%were aged above 35 . The sample of age group represented in this study corresponds to the national average of the country, as according to the Demographic and health survey 2016 [7].

Among this study population it was found that $8.1 \%$ of the participants had a preexisting medical condition. Although the number is not significant, this may be due to the fact that more complicated pregnancies with other medical illness prefer to attend ANC in a tertiary care center where this study was done.

Among the participants only $4.4 \%$ reported some form of domestic violence, although studies carried out in Nepal show that up to $13 \%$ women suffer from domestic violence [8].

Among participant, $80 \%$ reported that their pregnancy was planned. When inquired about the expected outcome regarding the sex of the baby from this pregnancy, 30.4\% had expectation for male child, $16.3 \%$ reported expectation for female child and $53.3 \%$ reported that they didn't have a specific preference. Among male and female sex, having higher expectation for a male child, which is a finding in this study as well, is a normal social norm due to our society still being patriarchal. 


\begin{tabular}{|c|c|c|c|c|}
\hline \multirow{2}{*}{ Parameters } & \multicolumn{4}{|c|}{ Anxiety } \\
\hline & & Present & Absent & P-value \\
\hline \multirow{2}{*}{ Address } & Rural & 2 & 32 & \multirow{2}{*}{0.516} \\
\hline & Urban & 11 & 90 & \\
\hline \multirow{2}{*}{ Marital Status } & Married & 13 & 120 & \multirow{2}{*}{1.000} \\
\hline & Widowed & 0 & 2 & \\
\hline \multirow{3}{*}{$\begin{array}{l}\text { Socioeconomic } \\
\text { Status } \\
\text { (Kuppuswamy Scale) }\end{array}$} & Upper middle & 7 & 32 & \multirow{3}{*}{0.092} \\
\hline & Lower middle & 4 & 72 & \\
\hline & Upper lower & 2 & 18 & \\
\hline \multirow{3}{*}{ Religion } & Hindu & 13 & 110 & \multirow{3}{*}{0.496} \\
\hline & Buddhist & 0 & 6 & \\
\hline & Muslim & 0 & 6 & \\
\hline \multirow{2}{*}{ Husband } & Stay's together & 7 & 73 & \multirow{2}{*}{0.676} \\
\hline & Doesn't stay together & 6 & 49 & \\
\hline \multirow{2}{*}{ Preexisting medical illness } & Yes & 3 & 8 & \multirow{2}{*}{0.073} \\
\hline & No & 10 & 114 & \\
\hline \multirow{2}{*}{ HITS } & Positive & 0 & 6 & \multirow{2}{*}{1.000} \\
\hline & Negative & 13 & 116 & \\
\hline \multirow{2}{*}{ Past history of mental illness } & Yes & 0 & 6 & \multirow{2}{*}{1.000} \\
\hline & No & 13 & 116 & \\
\hline \multirow{2}{*}{$\begin{array}{l}\text { Complications of previous } \\
\text { pregnancies }\end{array}$} & Yes & 7 & 42 & \multirow{2}{*}{0.225} \\
\hline & No & 6 & 80 & \\
\hline \multirow{2}{*}{ History of infertility } & Yes & 6 & 2 & \multirow{2}{*}{$<0.001$} \\
\hline & No & 7 & 120 & \\
\hline \multirow{2}{*}{ Planned pregnancy } & Yes & 9 & 100 & \multirow{2}{*}{0.275} \\
\hline & No & 4 & 22 & \\
\hline \multirow{3}{*}{$\begin{array}{l}\text { POG } \\
\text { (Period of Gestation) }\end{array}$} & 1 & 7 & 40 & \multirow{3}{*}{0.235} \\
\hline & 2 & 2 & 43 & \\
\hline & 3 & 4 & 39 & \\
\hline \multirow{2}{*}{ Pregnancy induced illness } & Yes & 8 & 12 & \multirow{2}{*}{$<0.001$} \\
\hline & No & 5 & 110 & \\
\hline \multirow{3}{*}{ Expected outcome } & Son & 6 & 35 & \multirow{3}{*}{0.410} \\
\hline & Daughter & 2 & 20 & \\
\hline & Any & 5 & 67 & \\
\hline
\end{tabular}

Table 3: Association of anxiety and different variables according to BAI.

The prevalence of moderate anxiety according to BAI was found to be $9.6 .90 .4 \%$ women reported no or low anxiety symptoms and none of the women reported severe anxiety symptoms. A metaanalysis published in 2017 looked at prevalence of antenatal anxi- 


\begin{tabular}{|l|c|c|c|c|}
\hline & B & S.E & t & p-value \\
\hline Age & 0.106 & 0.133 & 0.800 & 0.425 \\
\hline Marital status & 0.067 & 1.494 & 0.045 & 0.964 \\
\hline $\begin{array}{l}\text { History of } \\
\text { infertility }\end{array}$ & 10.779 & 2.401 & 4.490 & $<0.001$ \\
\hline $\begin{array}{l}\text { Complication of } \\
\text { previous } \\
\text { pregnancy }\end{array}$ & 1.338 & 1.192 & 1.123 & 0.264 \\
\hline $\begin{array}{l}\text { Planned pregnancy } \\
\text { Expected outcome }\end{array}$ & 0.578 & 1.587 & 0.364 & 0.716 \\
\hline HITS & 6.391 & 2.964 & 2.156 & 0.033 \\
\hline $\begin{array}{l}\text { Pregnancy induced } \\
\text { illness }\end{array}$ & 11.256 & 1.512 & 7.447 & $<0.001$ \\
\hline
\end{tabular}

high risk i.e., had some form of complication during the pregnancy including pregnancy induced illness like hypertension or diabetes mellitus.

\section{Correlates of anxiety in pregnancy}

Multiple regression was performed keeping total BAI score as the dependent variable and age, marital status, history of sub fertility, complications in previous pregnancy, unplanned pregnancy, expected outcome, HITS and pregnancy induced illness as dependent variable.

Our analysis showed that all these variables explained 39\%variance in BAI, i.e. $39 \%$ of the anxiety symptoms could be explained by the above variables. Out of all the independent variables only history of sub fertility, HITS score, and pregnancy induced illness were seen to be the statistically significant predictors of high BAI scores, as shown in table 4. In one study, multiple regression analysis also identified high risk pregnancy as a predictor of anxiety, which was a similar finding in our study. The same also however, identified maternal age at gestation as another important predictor of anxiety [11].

\section{Conclusion}

Antenatal anxiety is of great deal of importance because it affects not just the mother but also has impact on the health and development of the child as well affects the mother child bonding. This is also the predictors of anxiety in the post-natal period. Very little study has been conducted in our part of the world regarding such mental health issues in mothers and the studies have mostly focused in the post-partum period. Hence, this study aimed to estimate the prevalence of anxiety in the antenatal period so that extent of the problem could be identified and useful recommendations made.

variables. According to this study, women who had history of sul fertility had higher rates of anxiety as compared to women who did not have such history. Similar findings have been obtained from previous studies where women who conceived after assisted reproductive technique, after a period of sub fertility, had higher prevalence of anxiety [10].

Similarly, in this study, women who had a pregnancy induced illness had higher rates of anxiety symptoms then when compared to women who did not have such illness. Similar finding was reported from a study done by Razieh., et al. [11], where they found that higher prevalence of anxiety was seen in pregnancies which were

\section{Bibliography}

1. World Health Organization. Department of Mental Health and Substance Abuse. "Maternal mental health and child health and development in low and middle income countries: Report of the meeting held in Geneva, Switzerland, 30 January-1 February. Geneva". World Health Organization (2008).

2. Faisal-Cury A and P Rossi Menezes. "Prevalence of anxiety and depression during pregnancy in a private setting sample". Archives of Women's Mental Health 10.1 (2007): 25-32. 
3. Rwakarema Mechtilda., et al. "Antenatal depression is associated with pregnancy-related anxiety, partner relations, and wealth in women in Northern Tanzania: a cross-sectional study". BMC Women's Health 15.1 (2015): 1-10.

4. Chandran Mani., et al. "Post-partum depression in a cohort of women from a rural area of Tamil Nadu, India: Incidence and risk factors". The British Journal of Psychiatry 181.6 (2002): 499-504.

5. Beck AT., et al. "An inventory for measuring anxiety: Psychometric properties". Journal of Consulting and Clinical Psychology 56 (1988): 893-897.

6. Kohrt Brandon A., et al. "Validation of the Nepali version of beck anxiety inventory". Journal of Institute of Medicine 26.3 (2007).

7. Ministry of Health. New ERA and ICF. Nepal Demographic and Health Survey 2016. Ministry of Health, Nepal. Report number: FR336 (2017).

8. Axinn William G., et al. "Gender, traumatic events, and mental health disorders in a rural Asian setting". Journal of Health and Social Behavior 54.4 (2013): 444-461.

9. Dennis Cindy-Lee., et al. "Prevalence of antenatal and postnatal anxiety: systematic review and meta-analysis". The British Journal of Psychiatry 210.5 (2017): 315-323.

10. Hashemieh Chehreha., et al. "Assessment of anxiety in pregnancy following Assisted Reproductive Technology (ART) and associated infertility factors in women commencing treatment". Iranian Red Crescent Medical Journal 15.12 (2013).

11. Rezaee Razieh and Mahbobeh Framarzi. "Predictors of mental health during pregnancy". Iranian Journal of Nursing and Midwifery Research 19.7 (2014): S45.

Volume 5 Issue 7 July 2021

(C) All rights are reserved by Bhattarai G., et al. 